\title{
Tardive dyskinesia: clinical correlation with computed tomography in patients aged less than 60
} years

\author{
M BRAININ, Th REISNER, J ZEITLHOFER
}

From the Department of Neurology, Niederösterreichisches Landeskrankenhaus für Psychiatrie und Neurologie Klosterneuburg and from the CT Department, Neurological University Clinic, Vienna, Austria

SUMMARY In a prevalence study of 335 psychiatric in-patients 49 patients $(14.6 \%)$ with tardive dyskinesia were found. In view of the high prevalence of spontaneous dyskinetic syndromes in elderly patients only patients under 60 years were included $(n=21$; mean age: $44 \cdot 9)$. Clinical rating was performed with the AIMS-scale. CT measurements of ventricular enlargement and cortical atrophy were obtained. Tardive dyskinesia cases did not differ significantly from healthy controls, though some patients with severe dyskinesia showed signs of brain atrophy. These findings did not provide evidence to support neuropathological reports describing neuronal cell loss and midbrain gliosis in such patients. It is concluded that such structural brain changes in tardive dyskinesia patients are not detectable with present CT technology: they may either be due to concurrent aging processes or, in the case of younger patients, can be confirmed only by more functional methods of testing.

Tardive dyskinesia includes a wide variety of involuntary movements including orolingual dyskinesia, chorea, athetosis, dystonia, tics, and facial grimacing but excluding rhythmic tremor. It occurs in at least $10-20 \%$ of the patients exposed to neuroleptic drugs for more than a year. ${ }^{1}$ The phenomenology of this disorder has been repeatedly reviewed and expanded over the last few years. ${ }^{2-4} \mathrm{~A}$ major problem in diagnosis has been the higher prevalence of tardive dyskinesia in elderly patients and the difficulty of determining the prevalence of spontaneous dyskinetic movements in the normal population. Klawans and Barrs have recently determined such a baseline, showing that the prevalence of spontaneous lingual-facial-buccal dyskinesias is $0.8 \%$ between the age of 50 and 59 years, rising abruptly to $6 \%$ and $7.8 \%$ within the next two decades.

Address for reprint requests: Dr Michael Brainin, Neurologische Abteilung, Niederösterreichisches Landeskrankenhaus für Psychiatrie und Neurologie, Hauptstrasse 2, A-3400 Klosterneuburg, Austria.

Received 21 April 1983 Accepted 14 May 1983.
There have been several neuropathological reports of structural changes in the brain of patients with tardive dyskinesia, especially gliosis and neuronal degeneration in the upper midbrain and in the substantia nigra. However, these cannot be reliably correlated with the clinical disorder. Such changes were attributed to concurrent processes of aging and were therefore not necessarily thought to be a direct effect of prolonged neuroleptic medication. ${ }^{6}$

The present study was designed to answer the questions: do patients with tardive dyskinesia under the age of 60 years show morphological lesions on CT? Are there significant atrophic or gliotic changes compared to controls? Is there a correlation between the clinical severity of abnormal movements and the extent of brain atrophy in such patients?

\section{Material and method}

In a prevalence study of tardive dyskinesia in the Niederösterreichischen Landeskrankenhaus Klosterneuburg 335 psychiatric in-patients were examined for symptoms suggestive of tardive dys- 
kinesia. Rating was performed by the treating psychiatrists using the AIMS scale. ${ }^{1}$ Forty-nine patients with tardive dyskinesia of varying degree were found $(14.6 \%)$. Out of 132 male patients there were $20(15 \%)$ and out of 203 female patients there were $29(14.3 \%)$.

To exclude possible effects of aging, only patients up to 60 years of age were selected for further study ( $n=21 ; 13$ males and eight females). Their ages ranged from 20 to 59 years, the average age being 44.9 years. All patients had a history of neuroleptic therapy of at least two years duration. Consecutively, CT examinations were performed with a SOMATOM 2N (Siemens, matrix $256 \times 256$ ). At least eight serial slices were made of $8 \mathrm{~mm}$ thickness. In no case contrast enhancement was applied.

To evaluate atrophic changes three parameters were used. For the lateral ventricles the VentricleIndex-Ratio (VIR) and the Ventricle-Waist-Ratio (VWR) were used. The VIR is the ratio between the maximum width of the anterior horns and the maximum width of the internal diameter of the skull on the same slice. The VWR is the ratio between the minimal width of the cella media and the maximal internal diameter of the skull on the same slice. VIR and VWR are expressed as percentages. Average values and standard deviations of the VIR and VWR measurements were compared to a normal population under the age of 60 as previously published.? In addition, signs of cortical atrophy were evaluated with a simple yes/no judgement by two of the examiners (ThR and MB). Only when found by both examiners cortical atrophic changes were considered valid.

\section{Results}

In 21 patients under 60 years of age clinical rating was performed with the AIMS scale and the severity of abnormal movements as well as the severity of oro-facial movements was assessed. CT was performed in 15 of the 21 patients within two weeks of rating. Six patients either refused to have a CT done or were too anxious or psychotic to be included (see table).

Out of $\mathbf{1 5}$ patients only five had an abnormal CT scan. In three cases moderate internal hydrocephalus was found (cases $6,8,12$ ). In one case moderate atrophic changes were found infratentorially in combination with enlarged cerebro-spinal fluid spaces at the cerebral convexity (case 3 ). In one case unilateral calcification in the right pallidum was found (case 11). The average VIR (\%) was $26.01 \pm 4.55$ and the average VWR (\%) was $18 \cdot 08 \pm 5 \cdot 16$. For average values and standard deviations the $t$ test for independent probes was
Table 21 patients with tardive dyskinesia under the age of 60.

\begin{tabular}{|c|c|c|c|c|c|c|c|}
\hline$N r$. & Sex & $\begin{array}{l}\text { Age } \\
(y r)\end{array}$ & $S A M$ & $S O F M$ & $V I R$ & $V W R$ & $C A$ \\
\hline $\begin{array}{r}1 \\
2 \\
3 \\
4 \\
5 \\
6 \\
7 \\
8 \\
9 \\
10 \\
11 \\
12 \\
13 \\
14 \\
15 \\
16 \\
17 \\
18 \\
19 \\
20 \\
21\end{array}$ & $\begin{array}{l}\mathrm{m} \\
\mathrm{m} \\
\mathrm{m} \\
\mathbf{m} \\
\mathrm{m} \\
\mathrm{m} \\
\mathbf{f} \\
\mathbf{f} \\
\mathbf{f} \\
\mathbf{f} \\
\mathbf{f} \\
\mathrm{m} \\
\mathrm{m} \\
\mathrm{m} \\
\mathrm{m} \\
\mathrm{m} \\
\mathrm{m} \\
\mathrm{m} \\
\mathbf{f} \\
\mathrm{f} \\
\mathrm{f}\end{array}$ & $\begin{array}{l}51 \\
51 \\
29 \\
40 \\
23 \\
50 \\
51 \\
51 \\
56 \\
45 \\
54 \\
56 \\
37 \\
50 \\
50 \\
59 \\
48 \\
32 \\
20 \\
56 \\
35\end{array}$ & $\begin{array}{l}2 \\
2 \\
3 \\
2 \\
2 \\
3 \\
3 \\
2 \\
3 \\
3 \\
2 \\
4 \\
2 \\
3 \\
3 \\
1 \\
2 \\
1 \\
2 \\
3 \\
2\end{array}$ & $\begin{array}{r}8 \\
7 \\
14 \\
5 \\
4 \\
8 \\
13 \\
10 \\
12 \\
8 \\
4 \\
15 \\
6 \\
12 \\
11 \\
2 \\
5 \\
2 \\
8 \\
7 \\
1\end{array}$ & $\begin{array}{l}25 \cdot 3 \\
\overline{26 \cdot 8} \\
26 \cdot 3 \\
\overline{30 \cdot} \\
27 \cdot 4 \\
30 \cdot 3 \\
25 \cdot 0 \\
19 \cdot 3 \\
18 \cdot 7 \\
29 \cdot 9 \\
20 \cdot 9 \\
24 \cdot 6 \\
24 \cdot 3 \\
- \\
26 \cdot 5 \\
27 \cdot 3 \\
- \\
-\end{array}$ & $\begin{array}{l}\frac{17 \cdot 4}{20 \cdot 8} \\
21 \cdot 7 \\
\frac{28}{13 \cdot 3} \\
24 \cdot 1 \\
18 \cdot 8 \\
14 \cdot 8 \\
16 \cdot 2 \\
27 \cdot 3 \\
20 \cdot 0 \\
12 \cdot 3 \\
12 \cdot 1 \\
- \\
14 \cdot 7 \\
12 \cdot 1 \\
- \\
-\end{array}$ & $\begin{array}{l}\mathrm{n} \\
\mathrm{y} \\
\mathrm{n} \\
\mathrm{n} \\
\mathrm{n} \\
\mathrm{n} \\
\mathrm{n} \\
\mathrm{n} \\
\mathrm{n} \\
\mathrm{n} \\
\mathrm{n} \\
\mathrm{n} \\
-\mathrm{n} \\
\mathrm{n} \\
- \\
-\end{array}$ \\
\hline
\end{tabular}

SAM: Severity of abnormal movements. SOFM: Severity of oro-facial movements. SAM and SOFM are summarised from the AIMS scale. CT parameters: VIR: Ventricle-Index-Ratio; VWR: Ventricle-Waist-Ratio. VIR and VWR are expressed in percentages. CA: Cortical atrophy, $y=y e s ; n=$ no. For definitions and interpretation of results see text.

used, referring to values for normals under the age of $60 .^{7}$ No difference was found in VIR and VWR values, respectively $(t=0.011, \mathrm{~ns} ; t=5 \cdot 28$, ns). Consequently, no relationship could be established between severity of abnormal movements, severity of facial-oral movements and degree of atrophic changes as seen on CT, although four patients with comparatively high clinical scores also had some signs of brain atrophy.

\section{Discussion}

CT is an efficient instrument for assessment of diffuse or local atrophic changes in degenerative diseases of the brain. However, atrophic changes of the brain occur with normal aging. Therefore, the diagnosis of "brain atrophy" should not be based solely on CT data, but must include the results of clinical examination. It is also widely acknowledged that the presence of senile dementia of Alzheimer type or multi-infarct type may correlate well with diffuse atrophic changes in the brain as seen on CT, despite a considerable group overlap with controls. ${ }^{8}$ There are other data lacking this correlation ${ }^{10}$ and still others stating a clear-cut difference on CT between patients with dementia and normal controls. ${ }^{1}$ Even more controversial is the attempt to correlate the clinical extent of senile dementia with the extent of atrophy seen on CT. With positron emission tomo- 
graphy, however, preliminary studies have shown a relationship between the severity of dementia and the decrease of regional cerebral blood flow and local oxygen metabolism. ${ }^{12}$

Local atrophic changes of the brain as diagnosed with CT have been reported in several extrapyramidal system diseases. In Huntington's chorea striatal and cortical atrophy have been noted, though by no means in all patients and a search for early atrophy in siblings of such patients has yielded little of clinical significance. ${ }^{13}$ In Wilson's disease CT abnormalities included low attenuation within the putamen, widening of the anterior horns and cortical and brainstem atrophy. Atrophic changes as seen with CT were by no means visible in all patients but occurred most severely in patients with a relatively longer duration of untreated disease. ${ }^{14}$ Paroxysmal choreoathetosis has, in one case report, been linked to a low attenuation area in the white matter of a cerebral hemisphere. ${ }^{15}$ Acute carbon monoxide poisoning may, on CT, be detectable as bilateral basal ganglia lacunae and symmetrical white matter low density areas. ${ }^{16}$ Intracranial gliosis has also been described as a pathological finding on CT and can be due to various aetiologies. ${ }^{17}$ Finally, in chronic schizophrenia, no relationship between ventricle ratios and duration or diagnostic sub-group has been confirmed, ${ }^{18}$ although neuronal cell loss and gliosis in the periventricular structures of the diencephalon and the midbrain tegment have been found microscopically. ${ }^{19}$

Compared to clinical studies on tardive dyskinesia, neuropathological reports are rare and are mostly based on single case studies. There are reports of changes found at necropsy in the globus pallidus and putamen, ${ }^{20}$ as well as gliosis in the upper midbrain and caudate nucleus, ${ }^{21}$ in the inferior olive, ${ }^{22}$ and even neuronal cell loss in the cerebral cortex..$^{23}$ The series of Christensen $e t a l^{24}$ is still the most elaborate histological study on tardive dyskinesia. Neuronal cell degeneration and gliosis of the substantia nigra was found in 27 of 28 cases. All these reported changes have been interpreted as a possible toxic effect of the neuroleptic drugs, though their occurrence may primarily be due to events of aging and not to a direct effect of chronic neuroleptic medication. ${ }^{6}$

In this study no relationship between ventricular dilatation or cortical atrophy and occurrence of tardive dyskinesia was established. However, in some patients, where dyskinesia was pronounced, signs of brain atrophy were noted. This suggests that the neuroanatomical data on patients with tardive dyskinesia accumulated to date cannot be confirmed by means of present CT technology alone. Structural changes that possibly underlie tardive dyskinesia might more clearly be revealed by correlation with the results of functional methods of testing, such as neurophysiological investigations and the evaluation of receptor site dynamics.

\section{References}

${ }^{1}$ Task Force Report on Late Neurological Effects of Antipsychotic Drugs. Tardive Dyskinesia: Summary of a Task Force of the American Psychiatric Association. Am J Psychiat 1980;137:1163-72.

${ }^{2}$ Granacher Jr, RP. Differential diagnosis of tardive dyskinesia: an overview. Am J Psychiat 1981;138:128897.

${ }^{3}$ Weiner WJ, Nausieda PA, Glantz RH. Meige syndrome (blepharospasm-oromandibular dystonia) after longterm neuroleptic therapy. Neurology (Ny) 1981;31:1555-6.

${ }^{4}$ Burke RE, Fahn S, Jankovic et al. Tardive dystonia: late onset and persistent dystonia caused by antipsychotic drugs. Neurology (Ny) 1982;32:1335-46.

${ }^{5}$ Klawans HL, Barr A. Prevalence of spontaneous lingual-facial-buccal dyskinesias in the elderly. Neurology ( $\mathrm{Ny}$ ) 1982;32:558-9.

${ }^{6}$ Klawans HL, Goetz CG, Perlik S. Tardive dyskinesia: a review and update. Am J Psychiatry 1980;137:900-8.

${ }^{7}$ Reisner Th, Zeiler K, Strobl G. Quantitative Erfassung der Seitenventrikelbreite im CT-Vergleichswerte einer Normalpopulation. Fortschr Neurol Psychiat 1980;48:168-74.

${ }^{8}$ Wilson RS, Fox JH, Huckman MS, Bacon LD, Lobick JJ. Computed tomography in dementia. Neurology (Ny) 1982;32:1054-7.

9 Hubbard BM, Anderson JM. Age, senile dementia and ventricular enlargement. J Neurol Neurosurg Psychiatry 1981;44:631-5.

${ }^{10}$ Hughes CP, Gado M. Computed tomography and aging of the brain. Radiology 1981;139:391-6.

${ }^{11}$ Soininen H, Puranen M, Riekkinen PJ. Computed tomography findings in senile dementia and normal aging. J Neurol Neurosurg Psychiatry 1982;45:50-4.

${ }^{12}$ Frackowiak RSJ, Pozilli C, Legg NJ et al. Regional cerebral oxygen supply and utilization in dementia. A clinical and physiological study with oxygen-15 and positron tomography. Brain 1981;104:753-78.

${ }^{13}$ Oepen G, Ostertag CH. Diagnostic value of $\mathrm{CT}$ in patients with Huntington's Chorea and their offspring. J Neurol 1981;225:189-96.

14 Kendall BE, Pollock SS, Bass NM, Valentine AR. Wilson's disease: Clinical correlation with cranial computed tomography. Neuroradiology 1981;22:1-5.

${ }^{15}$ Gilroy J. Abnormal computed tomograms in paroxysmal kinesigenic choreoathetosis. Arch Neurol 1982;39:779-80.

${ }^{16} \mathrm{Kim} \mathrm{KS}$, Weinberg PE, Suh JH, Ho SU. Acute carbon monoxide poisoning. Computed tomography of the brain. AJNR 1980;1:399-403.

${ }^{17}$ Weisberg L. Computed tomographic findings of intracranial gliosis. Neuroradiology 1981;21:253-7.

${ }^{18}$ Gattaz WF, Kaspar S, Kohlmeyer K, Beckmann H. Die kraniale Computertomographie in der Schizo- 
phrenieforschung. Fortschr Neurol Psychiat 1981;49:286-91.

${ }^{19}$ Stevens JR. Neuropathology of schizophrenia. Arch Gen Psychiat 1982;39:1131-9.

${ }^{20}$ Poursines Y, Alliez J, Toga M. Syndrome parkinsonien consécutif á la prise prolonguée de chlorpromazine avec ictus mortel intercurrent. Aspect des lésion pallidales. Rev Neurol (Paris) 1959;100:745-51.

${ }^{21}$ Gross H, Kaltenbäck E. Hirnbefunde nach neuroleptischer Langzeitbehandlung. Zbl ges Neurol Psychiat
1967;188:400.

${ }^{22}$ Grünthal E, Walther-Büel H. Über Schädigung der Oliva inferior durch Chlorpromazin. Psychiat Neurol (Basel) 1960;140:249-57.

${ }^{23}$ Ule $G$, Struwe $O$. Hirnveränderungen bei Dyskinesie nach neuroleptischer Langzeitbehandlung. Nervenarzt 1979;49:268-70.

${ }^{24}$ Christensen E, Møller JE, Faurbye A. Neuropathological investigation of 28 brains from patients with dyskinesia. Acta Psychiat Scand 1970;46:14-23. 